Check for updates

Cite this: RSC Adv., 2017, 7, 54747

Received 21st September 2017 Accepted 7th November 2017

DOI: $10.1039 / \mathrm{c} 7 \mathrm{ra10457j}$

rsc.li/rsc-advances

\section{Revealing ruthenium and basicity synergetic effects in Ru-MgAl catalysts for isomerization of linoleic acid to conjugated linoleic acid}

\author{
Jiebo Chen, ${ }^{* a c}$ Liaoyuan Zhang, ${ }^{c}$ Xinyu Zheng $^{c}$ and Ying Zheng ${ }^{b}$ \\ $\mathrm{Ru}-\mathrm{MgAl}$ catalysts were prepared by co-precipitation at different $\mathrm{pH}$ values $(x=7-12)$, with the aims of \\ investigating the effect of $\mathrm{pH}$ on their catalytic performance for isomerization of linoleic acid to \\ conjugated linoleic acid and of understanding the relationship of basicity site and ruthenium activity site. \\ The results showed that strong basicity and highly dispersed ruthenium may be the active sites for \\ linoleic acid isomerization. Only if all three conditions, i.e., high Ru dispersion, appropriate SMSI effect \\ and high number of strong basicity sites, are fulfilled can highly effective active sites be formed for the \\ isomerization of linoleic acid to conjugated linoleic acid. A possible reaction mechanism for the \\ isomerization was also proposed.
}

\section{Introduction}

Conjugated linoleic acid (CLA) present in dairy products and beef is a collective term used to describe the mixture of positional and geometric isomers of linoleic acid with conjugated double bonds. The conjugated double bonds are located from positions from 6 and 8 to 12 and 14, respectively, thus including a total of 28 positional and geometric isomers. ${ }^{1}$ The special structure of conjugated linoleic acid makes it suitable for wide application in industries and in healthy foods. Conjugated linoleic acid is highly reactive towards polymerization, which makes it attractive for various industrial uses, for example, conjugated drying oils have faster drying rates, better resistance to water, and improved toughness. ${ }^{2}$ Much attention has been paid to the physiological effects of CLA. Three CLA isomers, cis9, trans-11 CLA; trans-10, cis-12 CLA; and trans-9, trans-11 CLA, have been recognized to have health effects, including decrease in body fat quantity and increase in muscle ${ }^{2}$ and anti-inflammatory, ${ }^{3}$ anticarcinogenic, ${ }^{4}$ growth-promoting, ${ }^{5}$ anti-diabetic ${ }^{6}$ and antiatherogenic effects. ${ }^{7}$ The amount of CLA in meat and dairy products can depend on the diet of the ruminant animals, but the amount is usually very low, in the range of $2-5 \mathrm{mg} \mathrm{g}^{-1}$ of total fat. ${ }^{8,9}$ Therefore, these foods are not likely to be a significant source of CLA. Nowadays, CLAs can be mass produced by microbial biosyntheses and chemical isomerization of linoleic

\footnotetext{
${ }^{a}$ National Engineering Research Center for Sugarcane, Fujian Agriculture and Forestry University, Fuzhou, Fujian 350002, China. E-mail: jiebo-chen@fafu.edu.cn; Fax: +86 59183851742; Tel: +8659183851742

${ }^{b}$ College of Chemistry and Chemical Engineering, Fujian Normal University, Fuzhou, Fujian 350007, China

${ }^{c}$ College of Life Sciences, Fujian Agriculture and Forestry University, Fuzhou 350002, China
}

acid. It has been suggested that CLAs can be prepared by isomerization of linoleic acid over a heterogeneous catalyst, leading to higher productivity and cleaner chemistry. ${ }^{10} \mathrm{~A}$ heterogeneous catalyst would be easier to filter and reuse, and environmental problems and separation difficulties can be avoided. Bernas and Kreich ${ }^{11-15}$ conducted many pathbreaking works on producing CLA using heterogeneous catalysts and the materials Ru, Pd, Ni, Pt, Rh, Pt-Rh, Ir, and Os supported on various supports were shown to be catalytically active for isomerization of linoleic acid to CLA. However, it can be found that hydrogen is required for a majority of heterogeneous catalytic process to form half-hydrogenated intermediates, which finally transform into CLAs. This requirement of halfhydrogenated intermediates led to the formation of unwanted hydrogenated by-products. ${ }^{16}$ Though the production of CLAs by heterogeneous catalysts without hydrogen is a difficult and complicated process, it can reduce the production of unwanted by-products. Therefore, Bernas et al. ${ }^{17}$ further developed an isomerization catalyst; they used $\mathrm{Ru} / \mathrm{C}$ catalyst for the isomerization of linoleic acid without the use of $\mathrm{H}_{2}$, but the CLA production rate was only $23 \mathrm{~g}$ (CLA) per $\mathrm{g}$ (metal) per h. Philippaerts et al. ${ }^{18}$ described $\mathrm{H}_{2}$-free production of CLA using $\mathrm{Ru}-$ loaded zeolite catalysts with high CLA production rate; however, the process needed negative pressure during the reaction itself and the catalysts synthesis process was complex. Having used $\mathrm{Ru}-\mathrm{MgAl}$ hydroxides for production of CLA in the absence of hydrogen, ${ }^{19,20}$ our productivity was as high as 438 $\mathrm{g}$ (CLA) per $\mathrm{g}$ (metal) per $\mathrm{h}$, and the main products were the three biologically active CLA isomers. In addition, almost no hydrogenated by-products were formed. The influence of $\mathrm{Mg} / \mathrm{Al} \mathrm{molar}$ ratio on $\mathrm{Ru}-\mathrm{MgAl}$ hydroxides prepared was investigated, demonstrating that $\mathrm{Ru}-\mathrm{MgAl}$ hydroxides with $\mathrm{Mg} / \mathrm{Al}$ molar ratio of $4: 1$ was the optimal material for the linoleic acid 
isomerization reaction. ${ }^{20}$ Having discussed the roles of $\mathrm{Ru}$ and basicity sites, we deemed that $\mathrm{Ru}-\mathrm{MgAl}$ was a bifunctional catalyst and the basicity sites together with ruthenium had a synergetic effect on catalytic activity. However, the catalytic reaction mechanism is still unclear. Which basic sites and ruthenium activity sites contribute to the catalysis activity and how does the synergetic effect of the two activity sites help the isomerization reaction need further study. It is well known that synthesis conditions of catalysts such as preparation methods, molar ratios of metals, and preparation $\mathrm{pH}$ value have significant effects on the structural properties of materials..$^{21-23}$ In particular, the $\mathrm{pH}$ value in the co-precipitation step is known to be a key factor for the successful formation of an active phase. It was found that the co-precipitation $\mathrm{pH}$ value could strongly influence the distribution of surface acidity, surface chemical state, distribution of metal particles, catalytic performance and so on. ${ }^{24-27}$ In this work, Ru-MgAlO hydroxides synthesized by coprecipitation with different $\mathrm{pH}$ values $(\mathrm{pH}=7-12)$, surface basicities, surface morphologies, $\mathrm{Ru}$ dispersion abilities, and surface chemical states were studied. Through the different coprecipitation conditions, the role of the basic sites and ruthenium in the catalytic reaction was investigated. We aimed to give insight into the origin of active sites and elucidate the synergy between ruthenium and basicity by revealing the catalytic reaction mechanism.

\section{Experimental}

Ru-MgAlO hydroxides were synthesized by calcination of hydrotalcite, which was prepared by co-precipitation at different $\mathrm{pH}$ values. $\mathrm{MgCl}_{2} \cdot 6 \mathrm{H}_{2} \mathrm{O}, \mathrm{AlCl}_{3} \cdot 6 \mathrm{H}_{2} \mathrm{O}$ and $\mathrm{RuCl}_{3} \cdot x \mathrm{H}_{2} \mathrm{O}$ were dissolved in $100 \mathrm{~mL}$ deionized water $(\mathrm{Mg} / \mathrm{Al}$ molar ratio $=4: 1$, content of $\mathrm{Ru}$ was $0.8 \mathrm{wt} \%$ ). The second solution contained certain amounts of $\mathrm{Na}_{2} \mathrm{CO}_{3}$ and $\mathrm{NaOH}\left(2\left[\mathrm{CO}_{3}{ }^{2-}\right]=\left[\mathrm{Al}^{3+}\right], 3\right.$ $\left.\left[\mathrm{CO}_{3}{ }^{2-}\right]=2\left[\mathrm{OH}^{-}\right]\right)$. Then, the two solutions were slowly added dropwise to a glass flask with stirring at $60{ }^{\circ} \mathrm{C}$ for $30 \mathrm{~min}$ at different $\mathrm{pH}$; the $\mathrm{pH}$ was set at $7,8,9,10,11$, and 12 . The content was transferred into a Teflon-coated stainless-steel autoclave and aged at $80{ }^{\circ} \mathrm{C}$ for $16 \mathrm{~h}$ under autogenous water vapor pressure. After $16 \mathrm{~h}$, the precipitate formed was filtered and washed thoroughly with hot distilled water until the filtrate was free from $\mathrm{Cl}^{-}$as tested using silver nitrate solution. The obtained filter cake was dried in an oven at $80{ }^{\circ} \mathrm{C}$ for $14 \mathrm{~h}$. For comparison, the sample labeled as HT was also synthesized as per the above-mentioned procedure without adding $\mathrm{RuCl}_{3}$ $\cdot x \mathrm{H}_{2} \mathrm{O}$ or $\mathrm{MgCl}_{2} \cdot 6 \mathrm{H}_{2} \mathrm{O}$. These samples were formed by calcination in air at $450{ }^{\circ} \mathrm{C}$ for $4 \mathrm{~h}$ at a heating rate of $10{ }^{\circ} \mathrm{C} \mathrm{min}{ }^{-1}$. Consequently, the catalysts were denoted as Ru-MgAlP $x$, where $x$ stands for the different co-precipitation $\mathrm{pH}$.

\subsection{Characterization of catalysts}

Powder X-ray diffraction (XRD) patterns of synthesized catalysts were recorded on a Philips X'Pert MPD system equipped with XRK 900 reaction chamber, using Ni-filtered $\mathrm{Cu} \mathrm{K} \alpha$ radiation $(\lambda=1.54056 \AA)$ over a $2 \theta$ range of $10-80^{\circ}$. Operating voltage and current were maintained at $40 \mathrm{kV}$ and $40 \mathrm{~mA}$, respectively.
Crystalline phases were identified by matching JCPDS files. $\mathrm{N}_{2}$ adsorption-desorption isotherm at $-196{ }^{\circ} \mathrm{C}$ was obtained using a gas adsorption analyzer (ASAP 2020M; Micromeritics, Inc.) Prior to $\mathrm{N}_{2}$ adsorption, the samples were previously degassed at $300{ }^{\circ} \mathrm{C}$ for $8 \mathrm{~h}$. BET specific areas were calculated from these isotherms using the BET method. Chemisorption study was carried out using an AutoChem 2920 instrument (Micromeritics) via the pulse method by introducing 5\% CO and 95\% He over a sample maintained at $25{ }^{\circ} \mathrm{C}$. The dispersion sizes of Pt particles were calculated from the cumulative volume of $\mathrm{CO}$ adsorbed during the pulse chemisorptions. To calculate metal dispersion, an adsorption stoichiometry of $\mathrm{CO} / \mathrm{Ru}=1$ was assumed. $\mathrm{CO}_{2}$-TPD studies of the samples were performed using a Micromeritics ASAP 2920 instrument equipped with a thermal conductivity detector (TCD). Samples (50 mg) were pretreated under helium stream at $450{ }^{\circ} \mathrm{C}$ for $2 \mathrm{~h}\left(10^{\circ} \mathrm{C} \mathrm{min}^{-1}\right.$, $\left.50 \mathrm{~mL} \min ^{-1}\right)$. Then, the temperature was decreased to $70{ }^{\circ} \mathrm{C}$

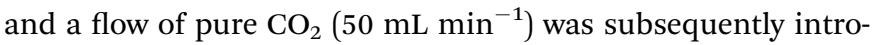
duced into the reactor for $1 \mathrm{~h}$. $\mathrm{CO}_{2}$-TPD study was carried out between 70 and $900{ }^{\circ} \mathrm{C}$ under helium flow $\left(10{ }^{\circ} \mathrm{C} \mathrm{min}^{-1}\right.$, $30 \mathrm{~mL} \min ^{-1}$ ). TPR studies of the samples were performed on a Micromeritics ASAP 2920 instrument equipped with a thermal conductivity detector (TCD). Before reduction, the sample (around $50 \mathrm{mg}$ ) was dried under helium flow at $120{ }^{\circ} \mathrm{C}$ for $4 \mathrm{~h}$. TPR was carried out between room temperature and $750{ }^{\circ} \mathrm{C}$ at a heating rate of $10{ }^{\circ} \mathrm{C} \mathrm{min}^{-1}$ under $10 \% \mathrm{H}_{2} / 90 \% \mathrm{Ar}\left(\mathrm{H}_{2}\right.$-TPR). Isopropyl alcohol gel $\left(-88^{\circ} \mathrm{C}\right)$ and a liquid nitrogen trap were used to remove water formed during tests. XPS measurements were performed using a Thermo Scientific Escalab250 with AlK $\alpha$ radiation $(1486.6 \mathrm{eV})$. The catalysts were first pressed into a disk and immediately transferred to the pretreatment chamber after fixing onto the sample holder. In the chamber, each sample was degassed overnight at $1 \times 10^{-6}$ Torr to remove volatile contaminants and was then transferred to an analyzing chamber for XPS analysis. The spectra were obtained at analyzer energy of $25.5 \mathrm{eV}$ and an electron take-off angle of $45^{\circ}$. The vacuum in the test chamber was maintained below $1.33 \times 10^{-8}$ Torr during collection. Binding energies were corrected for surface charging by referencing them to the energy of $\mathrm{C}$ 1s peak of the contaminant carbon at $284.6 \mathrm{eV}$.

\subsection{Catalysis measurements}

Isomerization of linoleic acid ( $>98 \%$ purity) was conducted in a stirred batch reactor $(25 \mathrm{~mL})$ that was provided with a reflux condenser and a heating jacket. In a typical experiment, $10 \mathrm{~mL}$ of $1 \mathrm{~mol} \mathrm{~L}^{-1}$ linoleic acid solvent and $0.4 \mathrm{~g}$ catalyst were charged all at once. Nitrogen was fed through the reactor before and during the isomerization to ensure an inert atmosphere and the reactor outlet was blocked by a fluid to prevent back-diffusion of oxygen into the reactor. The system was stirred at $400 \mathrm{rpm}$ to keep the catalyst uniformly dispersed in the reaction medium and to eliminate external mass-transfer problems. Catalytic tests were performed at $180{ }^{\circ} \mathrm{C}$ for $2 \mathrm{~h}$. For reusability of the catalysts, the spent catalyst was washed with $n$-hexane to remove adsorbed reactants/products from the surface of catalysts. After that, 
the catalyst was dried for $10 \mathrm{~h}$ at $80{ }^{\circ} \mathrm{C}$ and reused for the isomerization reaction.

\subsection{Products analysis}

The sample from the reactor was made to undergo methyl esterification by using $\mathrm{BF}_{3}$-methanol. After methyl esterification, $20 \mu \mathrm{L}$ of the sample was dissolved in $1 \mathrm{~mL}$ isooctane and analyzed by a gas chromatograph (GC, Agilent 7890A) equipped with a $100 \mathrm{~m}$ HP-88 column (inner diameter: $0.25 \mathrm{~mm}$ and film thickness: $0.25 \mu \mathrm{m}$ ), flame ionization detector (FID), and an autosample injector. The injector and detector temperature was $240{ }^{\circ} \mathrm{C}$. The column temperature was maintained at $120^{\circ} \mathrm{C}$ for $1 \mathrm{~min}$, increased at $10{ }^{\circ} \mathrm{C} \min ^{-1}$ to $175{ }^{\circ} \mathrm{C}$ and held there for $15 \mathrm{~min}$, increased at $5{ }^{\circ} \mathrm{C} \min ^{-1}$ to $210{ }^{\circ} \mathrm{C}$ and held there for 5 min and finally increased at $5{ }^{\circ} \mathrm{C} \min ^{-1}$ to $230{ }^{\circ} \mathrm{C}$ and held there for $5 \mathrm{~min}$. Heptadecane was used as the internal standard. Most CLA isomers were identified based on retention times using standard references. Other CLA isomers were identified based on previous data. ${ }^{28}$

\section{Results and discussion}

The composite oxides were used to isomerize linoleic acid to CLA. Fig. 1 shows CLAs yield as a function of $\mathrm{pH}$ values of catalysts in co-precipitation, indicating that co-precipitation $\mathrm{pH}$ value has a marked effect on catalyst activity. In the range of 7 to 11, the activity of the catalyst increased with increasing $\mathrm{pH}$ values. The $\mathrm{pH}$ value of 11 exhibited the best catalytic activity. However, the catalytic activity sharply dropped when the $\mathrm{pH}$ value increased to 12 and higher. For Ru-MgAlP11, 72\% yield was observed, while only $52 \%$ yield was obtained for $\mathrm{Ru}-$ MgAlP12.

Fig. 2 shows the XRD patterns of $\mathrm{Ru}-\mathrm{MgAlP} x$ catalysts prepared at different $\mathrm{pH}$ values of co-precipitation. The XRD patterns show peaks corresponding to MgO-type $\left(2 \theta=34.8^{\circ}\right.$, $43^{\circ}, 62.5^{\circ}$, JCPDS 01-1154) and $\mathrm{RuO}_{2}$-type phases $\left(2 \theta=28^{\circ}\right.$, $35.1^{\circ}, 54.4^{\circ}$, JCPDS $\left.40-1290\right)$. It is interesting to note that a different phase was formed depending on the $\mathrm{pH}$ value during the co-precipitation step. When $\mathrm{Ru}-\mathrm{MgAl}$ materials were synthesized below $\mathrm{pH}=8$, the $\mathrm{RuO}_{2}$ phase and $\mathrm{MgO}$ phase

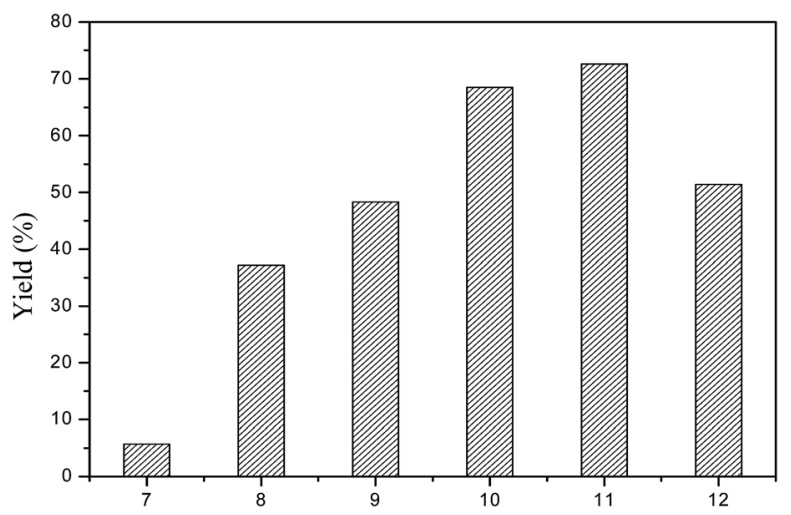

Fig. 1 CLA yield of Ru-MgAIPx catalysts as a function of $\mathrm{pH}$ value of co-precipitation.

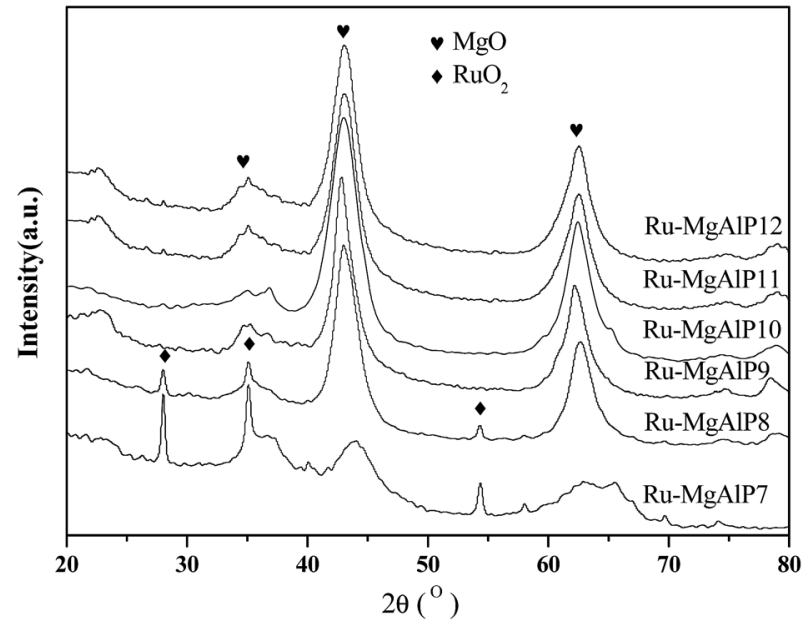

Fig. 2 XRD patterns of Ru-MgAlPx catalysts.

could be obtained. However, as $\mathrm{pH}$ increased, $\mathrm{RuO}_{2}$ diffraction peaks weakened and finally disappeared, while $\mathrm{MgO}$ diffraction peaks strengthened, which indicated that a part of the ruthenium oxide species was highly dispersed and the other part was segregated bulk $\mathrm{RuO}_{2}$ under $\mathrm{pH}=7$; as the $\mathrm{pH}$ values increased, ruthenium became highly dispersed on the surface of $\mathrm{Mg}(\mathrm{Al}) \mathrm{O}$ mixed oxides, but the particle size was too small $(<3 \mathrm{~nm})$ to detect by XRD. Meanwhile, diffraction peaks of $\mathrm{Al}_{2} \mathrm{O}_{3}$ were not obtained, which suggests that $\mathrm{Al}$ was also incorporated in the $\mathrm{MgO}$ lattice to form a solid solution. ${ }^{29}$

To determine the textural properties of $\mathrm{Ru}-\mathrm{MgAlP} x$ catalysts, low-temperature $\mathrm{N}_{2}$ adsorption/desorption experiments were implemented. As depicted in Fig. 3, a type IV isotherm with an obvious $\mathrm{H}_{2}$ hysteresis loop according to IUPAC is present, indicating typical mesoporous materials. On the basis of the adsorption/desorption isotherms, the textural properties are calculated and summarized in Table 1 . It can be noted that the

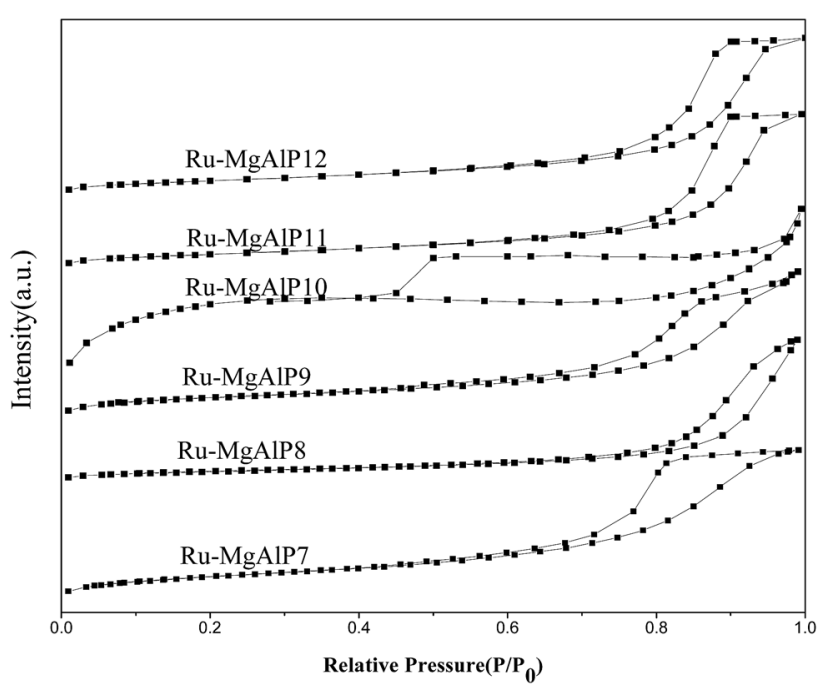

Fig. 3 Low-temperature $\mathrm{N}_{2}$ adsorption/desorption isotherms of $\mathrm{Ru}-$ MgAlPx catalysts. 
Table 1 Textural properties of Ru-MgAlPx catalysts

\begin{tabular}{|c|c|c|c|c|c|}
\hline Sample & $S_{\mathrm{BET}}\left(\mathrm{m}^{2} \mathrm{~g}^{-1}\right)$ & $V_{\mathrm{p}}\left(\mathrm{cm}^{3} \mathrm{~g}^{-1}\right)$ & $D_{\mathrm{Ru}}{ }^{a}(\%)$ & $d_{\mathrm{Ru}}{ }^{a}(\mathrm{~nm})$ & $S_{\mathrm{Ru}}{ }^{a}\left(\mathrm{~m}^{2} \mathrm{~g}^{-1}\right)$ \\
\hline Ru-MgAlP7 & 105 & 0.25 & 10.9 & 12.8 & 23 \\
\hline Ru-MgAlP8 & 132 & 0.30 & 20.0 & 6.9 & 42 \\
\hline Ru-MgAlP10 & 166 & 0.35 & 25.2 & 5.5 & 65 \\
\hline Ru-MgAlP11 & 155 & 0.32 & 42.2 & 3.3 & 78 \\
\hline Ru-MgAlP12 & 142 & 0.31 & 45.0 & 3.0 & 89 \\
\hline
\end{tabular}

${ }^{a}$ Calculated from $\mathrm{CO}$ chemisorption experiment and adsorption stoichiometry of $\mathrm{CO} / \mathrm{Ru}=1$.

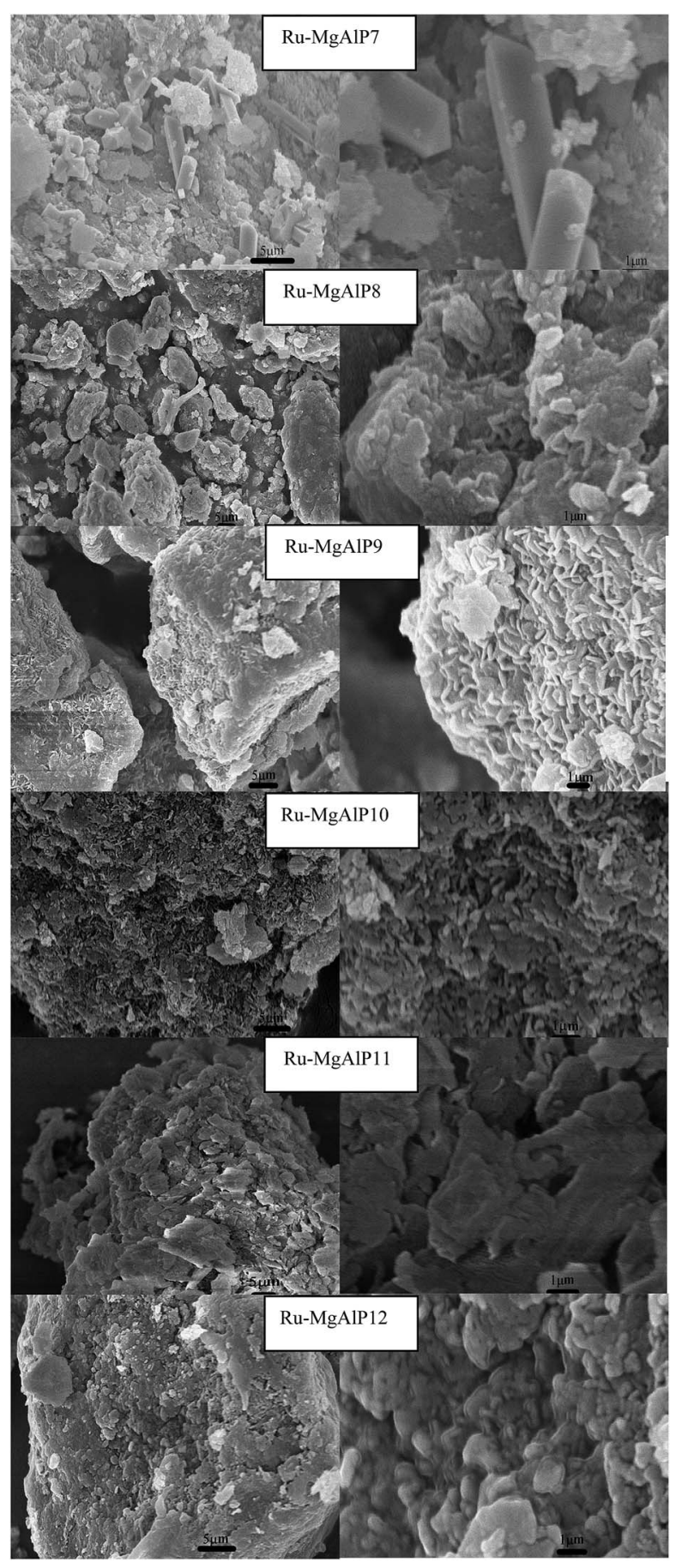

Fig. 4 SEM micrographs of Ru-MgAlPx catalysts. specific surface area $\left(S_{\mathrm{BET}}\right)$ of the Ru-MgAlP7 catalyst is markedly lower than those of the catalysts prepared in higher alkaline environments. It can be explained that under alkaline conditions, the increase of $-\mathrm{OH}$ groups leads to an increase in negative charge on the surface. Thus, an electrostatic repulsion force is established, and more mesopores are formed, resulting in a relatively higher $S_{\mathrm{BET}}$ than that of Ru-MgAlP7 catalysts. ${ }^{27}$

CO chemisorption was conducted to characterize the accessible surface $\mathrm{Ru}^{\mathrm{O}}$ atoms. The amount of $\mathrm{CO}$ adsorption is listed in Table 1. Using a $\mathrm{CO} / \mathrm{Ru}=1$ stoichiometry, the number of surface $\mathrm{Ru}^{\mathrm{O}}$ atoms can be calculated, from which $\mathrm{Ru}$ dispersion and particle size can be derived. It can be seen that the $\mathrm{Ru}-$ MgAlP7 catalysts exhibits the lowest Ru dispersion of $10.9 \%$, which is ascribed to the ruthenium forming segregated bulk $\mathrm{RuO}_{2}$. The $\mathrm{Ru}$ dispersion increases with $\mathrm{pH}$ values of coprecipitation. The highest $\mathrm{Ru}$ dispersion is obtained over the $\mathrm{Ru}-\mathrm{MgAlP} 12$ sample. It can be explained by that a high $\mathrm{pH}$ value may promote $\mathrm{Ru}$ species diffusion into the $\mathrm{MgO}$ lattice and prevent agglomeration. CLA yield increases with decreasing $\mathrm{Ru}$ crystallite size and with increasing Ru surface area.

The surface morphology of Ru-MgAlPx catalysts were observed by SEM analysis and the micrographs are presented in Fig. 4. The typical mesoporous morphology for all the samples can be noted, which is characteristic of solids consisting aggregates or agglomerates of particles forming pores. With increase in $\mathrm{pH}$ value of co-precipitation from 7 to 10 , the flakelike structure becomes much clearer. The clearest slit-shaped pores ascribed to nanoflakes interleaving with each other can be found over Ru-MgAlP9 and $\mathrm{Ru}-\mathrm{MgAlP10}$. As the $\mathrm{pH}$ value further increases to 12 , the flake-like morphology becomes inconspicuous. Therefore, it is believed that the co-precipitation $\mathrm{pH}$ value can strongly affect surface morphology of catalysts. Zeng $^{30}$ and $\mathrm{Xia}^{27}$ also reported a similar morphology for $\mathrm{LDH}$ materials.

The surface basicity of Ru-MgAlP $x$ catalysts was detected by $\mathrm{CO}_{2}$-TPD and is summarized in Fig. 5. Semiquantitative analysis was performed by deconvoluting the peaks with Gaussian curve fitting method. The calculated results are listed in Table 2. As can be seen from Fig. 5, all the samples exhibit three peaks at $110-200{ }^{\circ} \mathrm{C}, 200-400{ }^{\circ} \mathrm{C}$ and $450-750{ }^{\circ} \mathrm{C}$, which can be ascribed to the surface sites of weak $\left(\mathrm{OH}^{-}\right)$, medium (metal-oxygen pairs) and strong (isolated $\mathrm{O}^{2-}$ anions) basicity sites of $\mathrm{Ru}^{-}$ $\operatorname{MgAlP} x$, respectively. It can be seen that the temperatures of maximal peak intensity are almost constant regardless of coprecipitation $\mathrm{pH}$ value, while the peak areas vary greatly with 


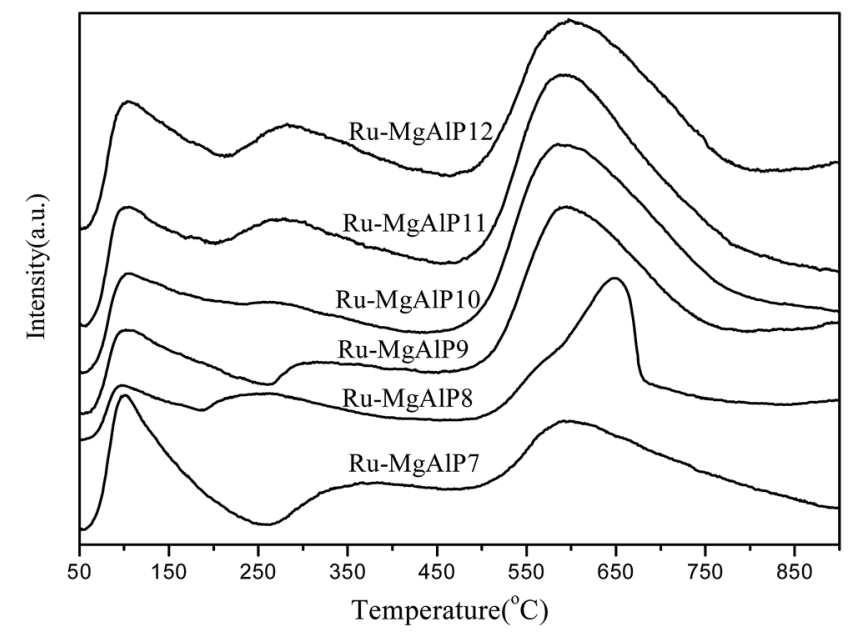

Fig. $5 \mathrm{CO}_{2}$-TPD profiles of Ru-MgAlPx catalysts.

$\mathrm{pH}$ value. The strong basicity sites increase as co-precipitation $\mathrm{pH}$ values of catalyst increase to $\mathrm{pH}=10$ and decrease with further increase in $\mathrm{pH}$. The strong basic sites are attributed to the migration of $\mathrm{Al}^{3+}$ into the $\mathrm{MgO}$ framework, which creates a cationic vacancy; the surface then acts as a sink for the vacancy and $\mathrm{Mg}^{2+}$ is removed from the surface by $\mathrm{Al}^{3+}$, leading to the formation of an additional surface $\mathrm{O}^{2-}$. In other words, the generation of strong basic sites is ascribed to the cleavage of the $\mathrm{Mg}-\mathrm{O}$ pairs. ${ }^{31}$ According to XRD results, the cleavage of the $\mathrm{Mg}-\mathrm{O}$ pairs may be due to $\mathrm{Al}^{3+}$ incorporated to crystal phase MgO.

The high activity of $\mathrm{RuO}_{2}$ heterogeneous catalysts for double bond isomerization can be explained by the fact that the catalysts can interact with the bonds of linoleic acid and are capable of activating the adjacent $\mathrm{C}-\mathrm{H}$ bond. These reactions are influenced by the concentration of chemisorbed hydrogen. ${ }^{10}$ These indicate that the ability of catalytic migration of double bonds is associated with the reducibility of the ruthenium oxides species. Fig. 6 shows $\mathrm{H}_{2}$-TPR profiles of $\mathrm{Ru}-\mathrm{MgAlP} x$ catalysts to characterize the reducibility of catalysts. There are three reduction peaks with maxima at around $130{ }^{\circ} \mathrm{C}, 170{ }^{\circ} \mathrm{C}$ and $230-280^{\circ} \mathrm{C}$. The two peaks at around $130^{\circ} \mathrm{C}$ and $170^{\circ} \mathrm{C}$ are assigned to the reduction of bulk $\mathrm{RuO}_{2}$ species. ${ }^{29}$ As the coprecipitation $\mathrm{pH}$ increases, the two low temperature reduction peaks decrease gradually and eventually disappear, which coincides with the XRD results. The peak at around $230-280^{\circ} \mathrm{C}$

Table 2 Amount of $\mathrm{CO}_{2}$ desorption from $\mathrm{CO}_{2}$-TPD profiles

\begin{tabular}{lllll}
\hline & \multicolumn{4}{l}{ Amount of $\mathrm{CO}_{2}$ desorption (unit area) } \\
\cline { 2 - 5 } Catalysts & $1^{\text {st }}$ peak & $2^{\text {nd }}$ peak & $3^{\text {rd }}$ peak & Total \\
\hline Ru-MgAlP7 & 1.23 & 1.96 & 3.40 & 6.59 \\
Ru-MgAlP8 & 0.57 & 1.65 & 4.04 & 6.26 \\
Ru-MgAlP9 & 0.66 & 1.34 & 5.40 & 7.40 \\
Ru-MgAlP10 & 0.75 & 0.92 & 5.67 & 7.34 \\
Ru-MgAlP11 & 0.77 & 1.81 & 4.84 & 7.42 \\
Ru-MgAlP12 & 0.87 & 2.05 & 4.31 & 7.23
\end{tabular}

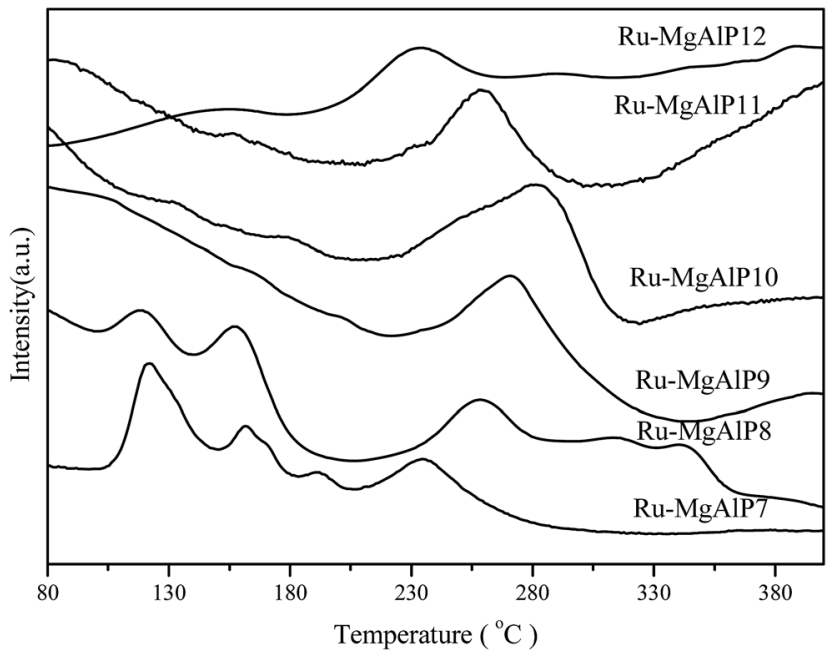

Fig. $6 \mathrm{H}_{2}$-TPR profiles of Ru-MgAlPx catalysts.

is assigned to the reduction of finely dispersed $\mathrm{RuO}_{2}$, which strongly interacts with the support (MgO). As can be seen from the $\mathrm{H}_{2}$-TPR profiles, the high temperature reduction peak gradually shifts to higher values, indicating that ruthenium and the support have strong metal-support interaction (SMSI) with increased $\mathrm{pH}$ of co-precipitation. ${ }^{32}$ One possible explanation is that as co-precipitation $\mathrm{pH}$ increases, more Ru species diffuse into MgO lattice, thus strengthening SMSI. Meanwhile, SMSI can transfer the protons adsorbed by strong basicity sites from $\mathrm{MgO}$ to the Ru species, which avoid the protons and carbanion recombination, thus accounting for improvement in catalytic performance.

To obtain information about the chemical state of the surface, XPS characterization was performed (Fig. 7). As the profiles show, $\mathrm{Ru} 3 \mathrm{~d}_{5 / 2}$ peak can be observed at $281.1-282.7 \mathrm{eV}$; the binding energy can be assigned to finely dispersed Ru metal particles. ${ }^{29}$ As co-precipitation $\mathrm{pH}$ increases, Ru binding energy decreases, which indicates that interaction between the $\mathrm{Ru}$ species and the support is strengthened. Ryndin et al. ${ }^{33}$ have

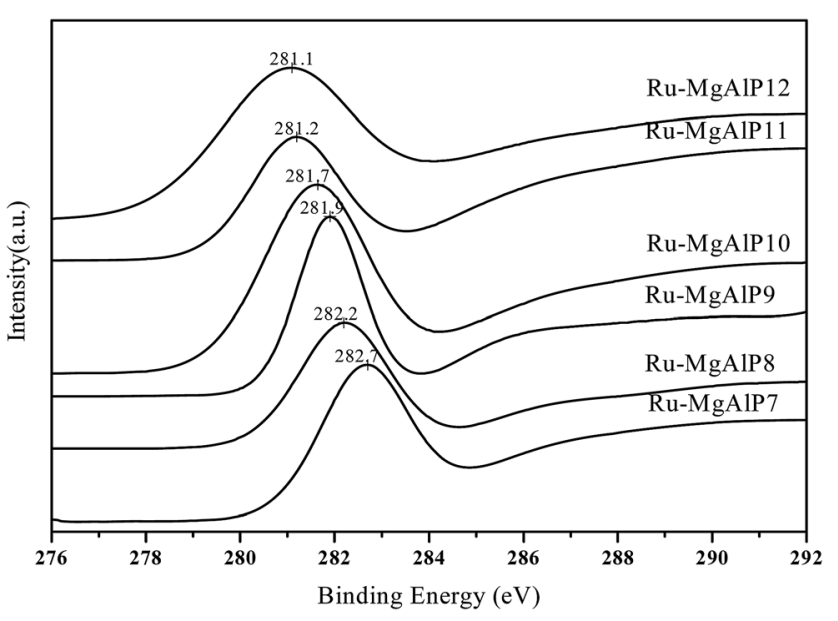

Fig. $7 \mathrm{Ru} 3 d_{5 / 2}$ XPS profiles of Ru-MgAlPx catalysts. 
also reported that the binding energy of $\mathrm{Pd}$ and $\mathrm{Pd} / \mathrm{C}$ increases with increasing Pd dispersion. Thus, the XPS results are generally in agreement with $\mathrm{CO}$ chemisorption measurement, confirming the formation of finely dispersed $\mathrm{Ru}$ metal on $\mathrm{Ru}-$ $\operatorname{MgAlP} x$. Meanwhile, we think that the decrease in Ru binding energy is also related to the strong basicity sites of the catalysts. $\mathrm{O}^{2-}$ strong basicity sites increases $\left(\mathrm{CO}_{2}-\mathrm{TPD}\right)$ rich electron transfer to $\mathrm{Ru}$, increasing the shielding effect and decreasing the binding energy of $\mathrm{Ru} 3 \mathrm{~d}_{5 / 2}$ decreased.

\section{Mechanism}

In order to understand the mechanism of isomerization catalytic reaction, the yields of CLAs with different catalysts were investigated. Interestingly, the CLA yield of Ru-AlP10 and MgAlP10 catalysts approached zero (Table 3, entries 7 and 8), suggesting that the basic site and the $\mathrm{Ru}$ are the active sites for the catalysis reaction. Comparing Ru dispersion (Table 1) with CLA yield, it can be found that the yields of CLAs increased with increase in $\mathrm{Ru}$ dispersion and the yields of Ru-MgAlP11 catalyst was the highest. However, the yield of CLA did not increase with $\mathrm{Ru}$ dispersion. To better investigate the relationship between catalytic activity and Ru dispersion, a plot of CLA yield versus $S_{\mathrm{Ru}}$ is shown in Fig. 8. It can be seen that no direct linear correlation between CLA yield and Ru surface area existed for this reaction.

Table 3 Yields of CLAs with different catalysts

\begin{tabular}{llllll}
\hline Entry & Catalyst & Solvent & $T\left[{ }^{\circ} \mathrm{C}\right]$ & $\mathrm{RA}$ & Yield (CLA)\% \\
\hline 1 & Ru-MgAlP7 & $n$-Decane & 180 & $\mathrm{~N}_{2}$ & 5.7 \\
2 & Ru-MgAlP8 & $n$-Decane & 180 & $\mathrm{~N}_{2}$ & 37.2 \\
3 & Ru-MgAlP9 & $n$-Decane & 180 & $\mathrm{~N}_{2}$ & 48.3 \\
4 & Ru-MgAlP10 & $n$-Decane & 180 & $\mathrm{~N}_{2}$ & 68.5 \\
5 & Ru-MgAlP11 & $n$-Decane & 180 & $\mathrm{~N}_{2}$ & 72.6 \\
6 & Ru-MgAlP12 & $n$-Decane & 180 & $\mathrm{~N}_{2}$ & 51.4 \\
7 & Ru-AlP10 & $n$-Decane & 180 & $\mathrm{~N}_{2}$ & 5 \\
8 & MgAlP10 & $n$-Decane & 180 & $\mathrm{~N}_{2}$ & $\approx 0$
\end{tabular}

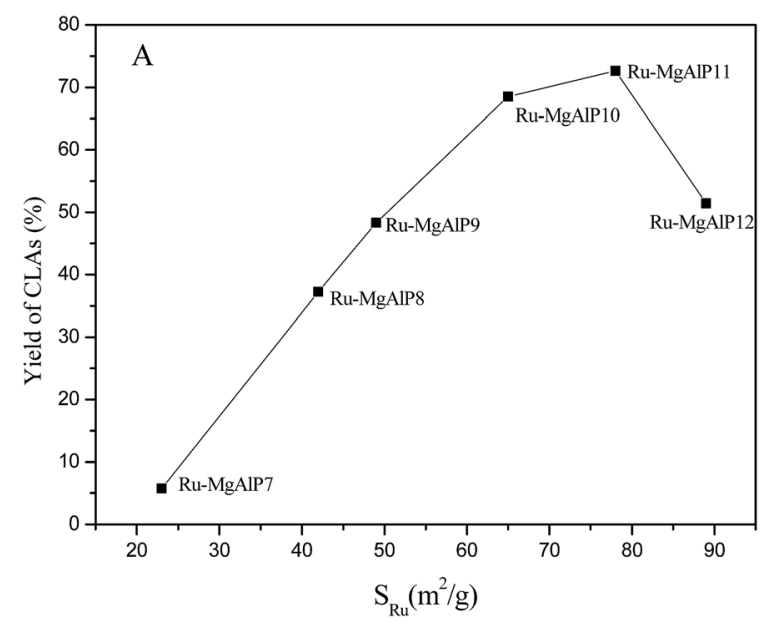

Fig. 8 Relationship between yield of CLAs and Ru surface area. $S_{R u}$ was determined by $\mathrm{CO}$-pulse chemisorptions.

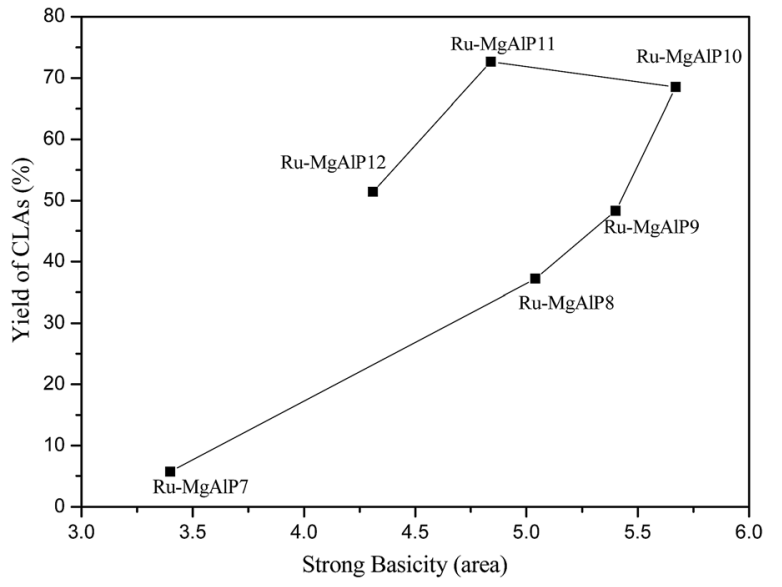

Fig. 9 Relationship between yield of CLAs and strong basicity sites.

The result indicated that Ru dispersion was not the sole factor affecting catalytic activity. However, $S_{\mathrm{Ru}}$ was an important parameter for isomerization catalytic activity.

In addition to basicity sites, we found that strong basicity plays an important role in catalytic isomerization of linoleic acid to CLA. Herein, the plot of CLA yield versus density of the stronger basicity sites was drawn, as shown in Fig. 9. Obviously, the CLA yield increased linearly with increase in density of strong basicity sites. Hence, it can be concluded that strong basicity sites are another important factor contributing to the increase in catalytic activity.

Hence, based on the above facts, it seems that strong basicity sites on the catalyst and ruthenium activity sites have a synergetic effect on catalytic activity. According to $\mathrm{H}_{2}$-TPR and $\mathrm{Ru}$ $3 \mathrm{~d}_{5 / 2}$ XPS characterization, we think that SMSI effect is the link between strong basicity sites and $\mathrm{Ru}$ activity sites. Their relationship can be described as shown in Fig. 10. The catalyst should possess a high $S_{\mathrm{Ru}}$ so that it exposes a large number of active sites; with the help of an appropriate SMSI effect, the Ru dispersion and active sites would increase; the catalyst's basicity needs to be stronger, which is beneficial for allyl-H migration

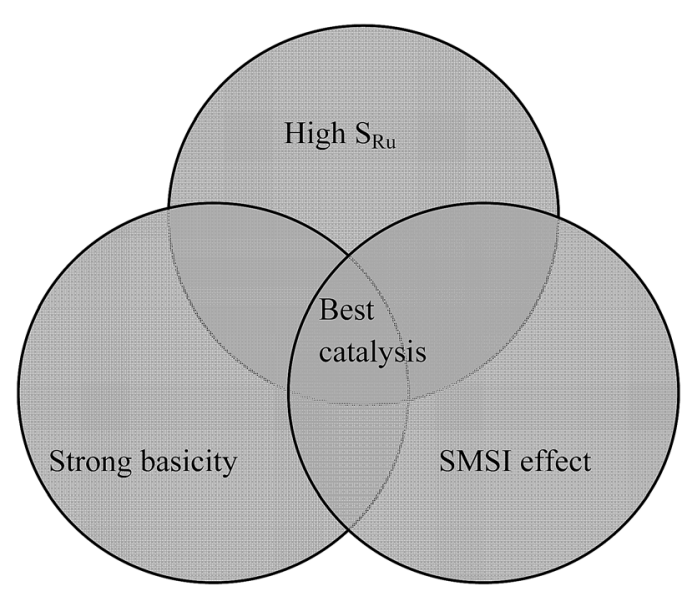

Fig. 10 Relationship of essential factors for a highly effective CLA synthesis catalyst. 


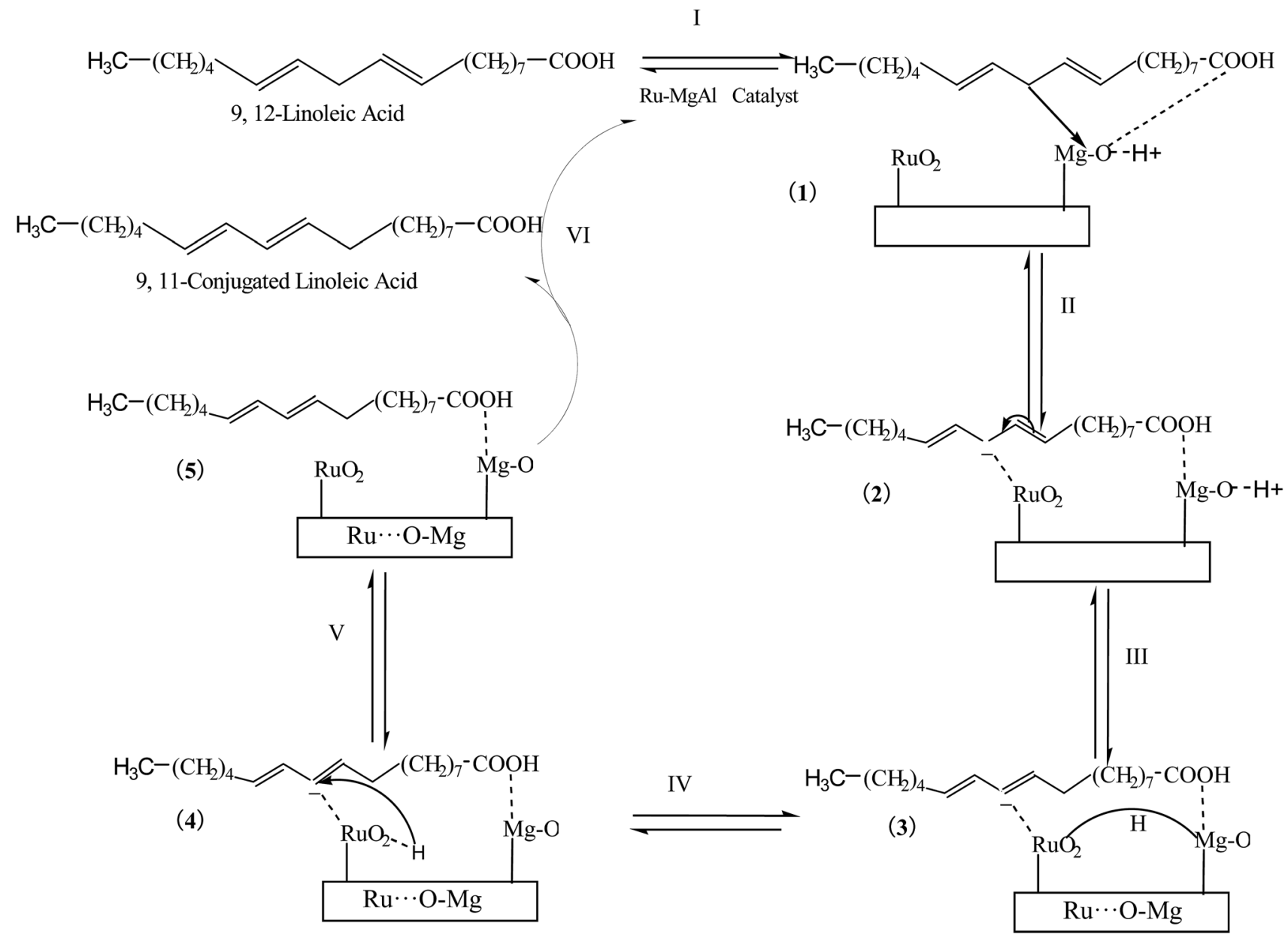

Fig. 11 Possible reaction mechanism for isomerization of linoleic acid to CLA using Ru-MgAl catalysts.

from $\gamma$-carbon atom to metal; only if all three factors take effect together on this catalyst would highly effective active sites be formed for the isomerization of linoleic acid to CLA.

According to the above facts, the possible reaction mechanism for isomerization of linoleic acid to CLA is proposed as follows (Fig. 11). Initially, the linoleic acid reacted with $\mathrm{Ru}-$ $\operatorname{MgAlP} x$ catalyst and the allyl-H migrated from $\gamma$-carbon to strong basicity site (step I) and the carboanion $\mathbf{1}$ was formed. The next step (II) is the interaction of carboanion 1 with $\mathrm{RuO}_{2}$ to form a $\pi$-complex 2 , which leads to double bond migration. ${ }^{34}$ It has already been suggested that ruthenium at its highest oxidation state favours double-bond isomerization. ${ }^{18}$ Then the hydrogen migrated from the allyl-H shifted from the basicity sites to $\mathrm{RuO}_{2}$ due to SMSI. Step IV involves migration of the hydrogen to the $\gamma$-carbon atom. The dissociation of active catalyst species from complex 5 in results the formation of CLA.

\section{Conclusions}

$\mathrm{Ru}-\mathrm{MgAlP} x$ catalysts prepared with different co-precipitation $\mathrm{pH}$ values $(x=7-12)$ have a strong effect on the specific surface area, surface morphology, distribution of surface basicity, dispersion of $\mathrm{RuO}_{2}$ particles and isomerization catalytic activity. The strong basicity sites and highly dispersed $\mathrm{RuO}_{2}$ particles were the active sites for linoleic acid isomerization. The strong basicity, highly dispersed $\mathrm{RuO}_{2}$ particles and SMSI effect have a synergistic influence on the catalytic isomerization reaction.

\section{Conflicts of interest}

There are no conflicts to declare.

\section{Acknowledgements}

The authors acknowledge the support from the Major Project of University-Industry Cooperation in Fujian Province (2015Y4003) and the Opening Foundation of National Engineering Research Center for Sugarcane.

\section{References}

1 Z. Gholami and K. K. Darani, An overview of conjugated linoleic acid: Microbial production and application, MiniRev. Med. Chem., 2014, 14, 734-746. 
2 A. Philippaerts, S. Goossens, P. A. Jacobs and B. F. Sels, Catalytic production of conjugated fatty acids and oils, ChemSusChem, 2011, 4, 684-702.

3 L. A. Penedo, J. C. Nunes, M. A. S. Gama, P. E. C. Leite, T. F. QuiricoSantos and A. G. Torres, Intake of butter naturally enriched with cis9, trans11 conjugated linoleic acid reduces systemic inflammatory mediators in healthy young adults, J. Nutr. Biochem., 2013, 24(12), 2144-2151.

4 M. McGowan, B. Eisenberg, L. Lewis, H. Froehlich, W. Wells, A. Eastman, N. Kuemmerle, K. Rosenkrantz, R. Barth, G. J. Schwartz, Z. Li, T. Tosteson, B. J. Beaulieu and W. Kinlaw, A proof of principle clinical trial to determine whether conjugated linoleic acid modulates the lipogenic pathway in human breast cancer tissue, Breast Cancer Res. Treat., 2013, 138(1), 175-183.

5 S. Tricon, G. C. Burdge, S. Kew, T. Banerjee, J. J. Russell, R. F. Grimble, C. M. Williams, P. C. Calder and P. Yaqoob, Effects of cis-9, trans-11 and trans-10,cis-12 conjugated linoleic acid on immune cell function in healthy humans, Am. J. Clin. Nutr., 2004, 80(6), 1626-1633.

6 N. C. Webb, E. A. R. Narvaez and H. Campos, Crosssectional study of conjugated linoleic acid in adipose tissue and risk of diabetes, Am. J. Clin. Nutr., 2012, 96(1), 175-181.

7 K. Valeille, J. Ferezou, M. Parquet, G. Amsler, D. Gripois, A. Q. Boulange and J. C. Martin, The natural concentration of the conjugated linoleic acid, cis-9, trans-11 in milk fat has antiatherogenic effects in hyperlipidemic hamsters, $J$. Nutr., 2006, 136(5), 1305-1310.

8 R. R. Dhiman, G. R. Anand, L. D. Satter and M. W. Pariza, Conjugated linoleic acid content of milk from cows fed different diets, J. Dairy Sci., 1999, 82, 2146-2156.

$9 \mathrm{~K}$. Koba and T. Yanagita, Health benefits of conjugated linoleic acid (CLA), Obes. Res. Clin. Pract., 2014, 8, e525-e532.

10 A. Bernas, N. Kumar, P. M. Arvela, B. Holmbom, T. Salmi and D. Y. Murzin, Heterogeneous catalytic production of conjugated linoleic acid, Org. Process Res. Dev., 2004, 8, 341-352.

11 M. Kreich and P. Claus, Direct conversion of linoleic acid over silver catalyst in the presence of $\mathrm{H}_{2}$ : An unusual way toward conjugated linoleic acid, Angew. Chem., Int. Ed., 2005, 44, 7800-7804.

12 A. Bernas, N. Kumar, P. Laukkanen, J. Vayrynen, T. Salmi and D. Y. Murzin, Influence of ruthenium precursor on catalytic activity of $\mathrm{Ru} / \mathrm{Al}_{2} \mathrm{O}_{3}$ catalyst in selective isomerization of linoleic acid to cis-9,trans-11 and trans10,cis-12 conjugated linoleic acid, Appl. Catal., A, 2004, 267, 121-133.

13 A. Bernas, P. Maki-Arvela, N. Kumar, B. Holnbom, T. Salmi and D. Y. Murzin, Heterogeneously catalytic isomerization of linoleic acid over supported ruthenium catalysis for production of anticarcinogenic food constituents, Ind. Eng. Chem. Res., 2003, 42, 718-727.

14 N. Chorfa, S. Hamoudi and K. Belkacemi, Conjugated linoleic acid formation via heterogeneous hydrogenation/ isomerization of safflower oil over mesostructured catalysts, Appl. Catal., A, 2010, 387, 75-86.
15 A. Bernas, N. Kumar, P. Maki-Arvela, N. V. Kulkova, B. Holmbom, T. Salmi and D. Y. Murzin, Isomerization of linoleic acid over supported metal catalysts, Appl. Catal., A, 2003, 245, 257-275.

16 R. V. Salamon, E. V. Visi, C. D. Andras, Z. C. Kiss and J. Csapo, Synthetic methods for obtaining conjugated linoleic acids(CLA) by catalysis, Acta Univ. Sapientiae, Aliment., 2012, 5, 32-51.

17 A. Bernas, N. Kumar, P. Maki-Arvela, B. Holmbom, T. Salmi and D. Y. Murzin, Heterogeneous catalytic production of conjugated linoleic acid, Org. Process Res. Dev., 2004, 8, 341-362.

18 A. Philoppaerts, S. Goossens, W. Vermandel and M. Tromp, Design of Ru-zeolites for hydrogen-free production of conjugated linoleic acids, ChemSusChem, 2011, 4, 757-767.

19 J. B. Chen, X. X. Chen, Y. Zheng and Q. L. Li, Synergetic effect of ruthenium and basicity sites in the $\mathrm{Ru}-\mathrm{MgAl}$ catalyst for hydrogen-free production of conjugated linoleic acids, $R S C$ Adv. , 2015, 5, 20248-20255.

20 J. B. Chen, Y. Zheng, W. Z. Lin, L. Y. Zhang and Z. Y. Cai, Influence of $\mathrm{Mg} / \mathrm{Al}$ Molar Ratio on the Structures and Properties of Ru-MgAlx Catalysts for Isomerization Linoleic Acid, Chin. J. Struct. Chem., 2017, 36(3), 522-532.

21 X. B. Zhang, L. Zhong, Q. H. Guo, H. Fan, H. Y. Zheng and K. C. Xie, Influence of the calcination on the activity and stability of the $\mathrm{Cu} / \mathrm{ZnO} / \mathrm{Al}_{2} \mathrm{O}_{3}$ catalyst in liquid phase methanol synthesis, Fuel, 2010, 89, 1348.

22 Z. Mosayebi, M. Rezaei, N. Hadian, F. Z. Kordshuli and F. Meshkani, Low temperature synthesis of nanocrystalline magnesium aluminate with high surface area by surfactant assisted precipitation method: effect of preparation conditions, Mater. Res. Bull., 2012, 47, 2154.

23 S. Salem, Application of autoignition technique for synthesis of magnesium aluminate spinel in nanoscale: influence of starting solution $\mathrm{pH}$ on physicochemical characteristics of particles, Mater. Chem. Phys., 2015, 155, 59.

24 Y. J. Jeong, I. Kim, J. Y. Kang, H. Jeong, J. K. Park, J. H. Park and J. C. Jung, Alcohol-assisted low temperature methanol synthesis from syngas over $\mathrm{Cu} / \mathrm{ZnO}$ catalysts: Effect of $\mathrm{pH}$ value in the co-precipitation step, J. Mol. Catal. A: Chem., 2015, 400, 132-138.

25 J. C. Jung, H. Kim, A. S. Choi, Y.-M. Chung, T. J. Kim, S. J. Lee, S.-H. Oh and I. K. Song, Effect of $\mathrm{pH}$ in the preparation of $\gamma$ $\mathrm{Bi}_{2} \mathrm{MoO}_{6}$ for oxidative dehydrogenation of n-butene to 1,3 butadiene: correlation between catalytic performance and oxygen mobility of $\gamma-\mathrm{Bi}_{2} \mathrm{MoO}_{6}$, Catal. Commun., 2007, 8, 625.

26 J. C. Jung, H. Lee, H. Kim, Y.-M. Chung, T. J. Kim, S. J. Lee, S.-H. Oh, Y. S. Kim and I. K. Song, Effect of $\mathrm{pH}$ in the preparation of $\mathrm{Ni}_{9} \mathrm{Fe}_{3} \mathrm{Bi}_{1} \mathrm{Mo}_{12} \mathrm{O}_{51}$ for oxidative dehydrogenation of $\mathrm{n}$-butene to 1, 3-butadiene: correlation between catalytic performance and oxygen mobility of $\mathrm{Ni}_{9} \mathrm{Fe}_{3} \mathrm{BiMo}_{12} \mathrm{O}_{51}$, Catal. Commun., 2008, 9, 943.

27 K. Xia, W. Z. Lang, P. P. Li, X. Yan and Y. J. Guo, The properties and catalytic performance of $\mathrm{PtIn} / \mathrm{Mg}(\mathrm{Al}) \mathrm{O}$ catalysts for the propane dehydrogenation reaction: Effects of $\mathrm{pH}$ value in preparing $\mathrm{Mg}(\mathrm{Al}) \mathrm{O}$ supports by the coprecipitation method, J. Catal., 2016, 338, 104-114. 
28 A. Bernas, N. Kumar, P. M. Arvela, N. V. Kul'kova, B. Holmbom, T. Salmi and D. Y. Murzin, Isomerization of linoleic acid over supported metal catalysts, Appl. Catal., A, 2003, 245, 257-275.

29 D. L. Li, R. L. Li, M. M. Lu, X. Y. Lin, Y. Y. Zhan and L. L. Jiang, Carbon dioxide reforming of methane over $\mathrm{Ru}$ catalysts supported on $\mathrm{Mg}-\mathrm{Al}$ oxide: A highly dispersed and stable Ru/Mg (Al) O catalyst, Appl. Catal., B, 2017, 200, 566-577.

30 S. B. Zeng, X. L. Xu, S. K. Wang, Q. K. Gong, R. J. Liu and $\mathrm{Y}$. Yu, Sand flower layered double hydroxides synthesized by co-precipitation for $\mathrm{CO}_{2}$ capture: morphology evolution mechanism, agitation effect and stability, Mater. Chem. Phys., 2013, 140, 159-167.

31 G. D. Wu, X. L. Wang, W. Wei and Y. H. Sun, Fluorinemodified Mg-Al mixed oxides: A solid base with variable basic sites and tunable basicity, Appl. Catal., A, 2010, 377, 107-113.

32 J. C. Colmenares, A. Magdziarz, M. A. Aramendia, A. Marinas, J. M. Marinas, F. J. Urbano and J. A. Navio, Influence of the strong metal support interaction effect (SMSI) of $\mathrm{Pt} / \mathrm{TiO}_{2}$ and $\mathrm{Pd} / \mathrm{TiO}_{2}$ systems in the photocatalytic biohydrogen production from glucose solution, Catal. Commun., 2011, 16, 1-6.

33 Y. A. Ryndin, M. V. Stenin, A. I. Boronin, V. I. Bukhtiyarov and V. I. Zaikovshii, Effect of $\mathrm{Pd} / \mathrm{C}$ dispersion on its catalytic properties in acetylene and vinylacetylene hydrogenation, Appl. Catal., 1989, 54(1), 277-288.

34 H. Y. Li, P. Min and B. H. Chen, DFT study on the double bond rearrangement mechanism of cis-2-butene catalyzed by $3 \mathrm{~T}$ cluster model of zolite, Acta Chim. Sinica, 2006, 64(16), 1676-1680. 